\title{
Method of Precipitating and Preventing Some Migraine Attacks
}

\author{
J. N. BLAU,* M.B., B.S., M.R.C.P. ; J. N. CUMINGS,** M.D., F.R.C.P., F.C.PATH.
}

Brit. med. F., 1966, 2, 1242-1243

Research into migraine has been hindered by the lack of a method whereby a typical attack can be produced with some degree of certainty. We present our experience in a trial of fasting in a series of subjects known to have migraine.

Many people when hungry experience a sensation of coldness and become pale. Conversely, after a large meal the majority will feel physically warm and may have red glowing faces. In some way, at present awaiting physiological elucidation, hunger and satiety are accompanied by changes in the autonomic control of the blood supply to the face. Missing a meal or going without food for a long time may also give rise, in some people, to a dull headache at the vertex. This was noted by Moench (1951) and by Marks and Rose (1965), who associated the pain with hypoglycaemia. However, in predisposed subjects similar circumstances may give rise to a migrainous headache. Critchley and Ferguson (1933), in their classical paper on migraine, wrote: "The missing of a meal in the course of a busy day, unwonted exercise 'on an empty stomach,' are not uncommonly cited as causes of an attack. One person sustained his severest bout after deliberately avoiding food for 24 hours while continuing his normal work." A year later Critchley (1934), writing on the treatment of the condition, stated: "A full dose of glucose or of cane sugar may be efficacious-particularly in those apparently brought on by hunger."

In order to investigate this potential organic precipitant of migraine, two patients and 10 volunteers, all of whom had migraine, were fasted for a period of 19 hours, during which time blood sugars were measured at intervals.

\section{Subjects and Methods}

The two patients came to one of our outpatient clinics (J. N. B.) and among other complaints mentioned that they had had paroxysmal throbbing headaches associated with nausea and photophobia. Direct inquiry elicited that their headaches came on after missing a meal. The 10 volunteeers were all working in various departments at the National Hospital for Nervous Diseases, Queen Square. In this second group, none were attending their family practitioner or a hospital clinic for treatment of their migraine. They were asked if they would take part in the trial while continuing their normal hospital work.

Identical procedures were carried out on two days, on one of which the volunteer ate and drank normally, while on the other day, usually a week later, no food was taken after 10 p.m. on the night before the test procedures. Water, tea, or coffee without sugar or milk was permitted. Blood was taken at 10 a.m., 12 noon, 1, 2, 4, and 5 p.m. on the days of the test. The period of fasting was 19 hours (10 p.m. to 5 p.m.), after which food was allowed.

Symptoms of physical sensations were recorded by each of the volunteers. Headaches were graded as follows: $0=$ no headache; $+=$ awareness or unpleasant sensation in the head without pain $;++=$ an ache, whether localized or generalized ; $+++=$ throbbing headache; $+++=$ throbbing headache with either nausea or photophobia. Other symptoms, such as

- The National Hospitals for Nervous Discases and the Institute of Neurology, Queen Square, London. feeling cold, sweating, hunger, and lack of concentration, were also noted. The two patients were closely observed while they were inpatients, and we are indebted to Dr. Shirley Wray for her detailed notes.

The blood sugars were estimated daily in one batch by the method of Asatoor and King (1962).

\section{Results}

None of the subjects developed a headache on the control day. Migraine of a type characteristic for the individual was precipitated on the fast days in the two patients and in four of the volunteers. One of these four volunteers developed a throbbing headache with pallor, nausea, and increased salivation characteristic of his attacks, but did not vomit or have diarrhoea, which he usually experienced in a "full-blown" attack. He managed to abort a complete attack by taking some food at 5 p.m., and then went to sleep for an hour, waking exhausted but free from headache. Another three volunteers developed a headache after they had taken food. Table I shows details of the subject's age, sex, the absence or presence of headache, and whether the latter was expected or not.

We have charted the time of the precipitated migraines graphically (see Chart). Blood-sugar levels on control days

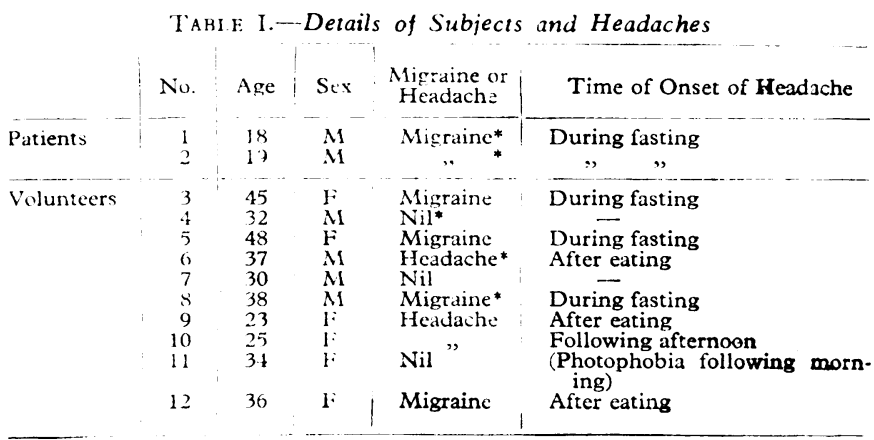

- Expected migraine

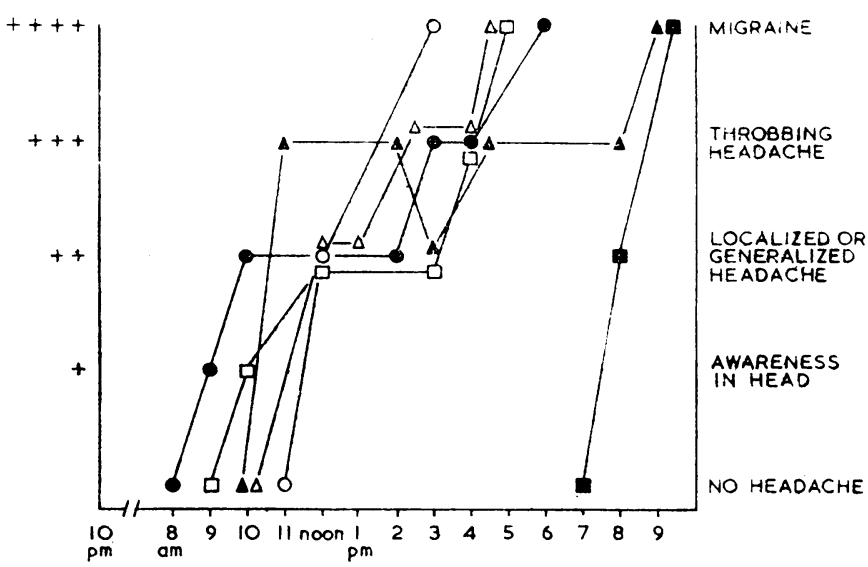

Time of onset and development of migraine in six subjects during a 19-hour fast from 10 p.m. to 5 p.m. next day. $O=$ Subject 1 .

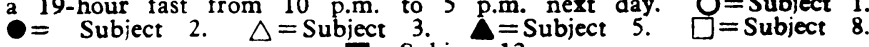
$=$ Subject 12 
showed, in all except one subject (No. 7), the normal fluctuations associated with meals, with figures rising to over 84 $\mathrm{mg} . / 100 \mathrm{ml}$. in 11 subjects, and over $90 \mathrm{mg} . / 100 \mathrm{ml}$. in 10 subjects (exception No. 10). An analysis of blood-sugar levels in the 12 subjects on the rest days is shown in Table II. All had typically flat curves, though there were minor variations during the day. One subject (No. 7) showed figures higher than on the control day; we cannot account for this discrepancy. Attention must be drawn to the fact that three out of the nine who developed some variety of headache did not begin to have pain until after they had eaten, when presumably their blood sugar had begun to rise.

\begin{tabular}{|c|c|c|c|c|c|}
\hline \multirow{2}{*}{ No. } & \multirow{2}{*}{ Attack } & \multicolumn{4}{|c|}{ Blood Sugars (mg./100 ml.) } \\
\hline & & 10 a.m. & Lowest & Highest & Average \\
\hline $\begin{array}{r}1 \\
2 \\
3 \\
4 \\
5 \\
6 \\
7 \\
8 \\
9 \\
10 \\
11 \\
12\end{array}$ & $\begin{array}{r}++++ \\
++++ \\
++++ \\
0 \\
++++ \\
++ \\
+0 \\
++++ \\
+++ \\
+++ \\
+0 \\
++++\end{array}$ & $\begin{array}{l}45 \\
67 \\
60 \\
70 \\
64 \\
72 \\
91 \\
62 \\
77 \\
65 \\
62 \\
64\end{array}$ & $\begin{array}{l}44 \\
58 \\
51 \\
66 \\
63 \\
60 \\
77 \\
59 \\
73 \\
41 \\
55 \\
64\end{array}$ & $\begin{array}{l}56 \\
71 \\
67 \\
76 \\
74 \\
75 \\
91 \\
72 \\
82 \\
65 \\
68 \\
75\end{array}$ & $\begin{array}{l}51 \\
67 \\
60 \\
74 \\
68 \\
68 \\
85 \\
62 \\
77 \\
59 \\
63 \\
67\end{array}$ \\
\hline
\end{tabular}

A common symptom was difficulty in concentration. Restlessness was a feature in some. Two found that walking worsened the headache, while one found the converse effect.

\section{Discussion}

We have demonstrated that 6 out of 12 subjects had an attack of migraine on the fast day, and that a further three developed headache, one of these occurring next day. Dehydration was not a factor, since the subjects were permitted to take fluids. Since fasting or missing a meal is a known factor in some migraine sufferers (Brain, 1962), and glucose is one of the major metabolites of the brain, we are postulating that a low blood sugar persisting for a sufficient period of time is a factor in causing migraine in some people. Our observations bear comparison with those of Gray and Burtness (1935), who found that a glucose-tolerance test of five hours' duration was associated with a headache when the blood sugar was reduced to between 60 and $90 \mathrm{mg} . / 100 \mathrm{ml}$. We agree with their conclusion that hypoglycaemia is a trigger factor in migraine. Moreover, Wilkinson (1949) produced 11 headaches in 13 "migrainoid patients" when carrying out a five-hour glucosetolerance test. He found that the headache began in the third to fourth hour, when the blood sugar was at its lowest, between 17 and $53 \mathrm{mg} . / 100 \mathrm{ml}$. We recently had a volunteer in whom an attack followed a simple two-and-a-half-hour glucosetolerance test. We propose to investigate this aspect further.

We do not believe that alteration of the blood sugar has a direct effect on the blood vessels of the meninges or of the face, although undoubtedly it does secondarily affect the circulation, as shown by the change in the colour of the face to be observed in many people after a large meal. This alteration in the calibre of the vessels or blood flow must be mediated either by a humoral mechanism or more likely through the autonomic neural control of the regional blood supply.
It is generally held that there is a psychogenic basis to migraine. Be that as it may, in all migrainous subjects there must be a common organic basis that gives rise to the autonomic disturbances that produce pallor, nausea, and vomiting, photophobia, and paroxysmal headaches. It is possible that hypoglycaemia for a period of time results in hypothalamic stimulation affecting central vasomotor control, which in turn gives rise to a chain reaction in predisposed subjects.

We wish to stress that persistent hypoglycaemia is not the cause of all migraine headache, not even in those subjects in whom this plays a part. We believe some patients have some of their attacks fired off by persistent hypoglycaemia. It may well be that the period of hypoglycaemia differs in individual subjects before an attack is initiated. The number of patients in whom this is a factor is uncertain and requires further investigation.

Eating is an obvious and easy method of preventing attacks. It has been our experience in the clinic that in some patients the taking of regular meals prevents at least a proportion of attacks. However, once an attack has developed to a certain degree glucose administration may not stop its progression.

One of the problems in the investigation of migraine, be it mechanism or treatment, is the difficulty in predicting when an attack may occur. Although this is a highly selected series, fasting provides a method of inducing migraine headaches in a certain proportion of people.

\section{Summary and Conclusion}

We have precipitated attacks of migraine in 6 out of 12 subjects by fasting from 10 p.m. one evening until 5 p.m. the following afternoon. Awareness in the head became apparent in the majority between 9 a.m. to 12 noon, which changed to a generalized or localized ache within the next hour or two, and some hours later developed into a throbbing pain accompanied by pallor, nausea or vomiting, and photophobia. In addition two volunteeers had a headache in the evening after a light meal, and a third during the next day.

We propose that some patients have some of their attacks of migraine ñred off by missing a meal, and that this is related to a low blood sugar, which must persist in that individual for a certain length of time to cause a headache. How this affects the blood vessels of the head and meninges requires further elucidation, as does the undue susceptibility of migraine sufferers to their complaint.

Our thanks are due to those who volunteered to take part in the trial, to Miss J. Quick for technical assistance, and to the Department of Medical Illustration of the Institute of Neurology, London.

\section{REFERENCES}

Asatoor, A. M., and King, E. J. (1962). In H. Varley's Practical Clinical Biochemistry, 3rd ed., p. 35 . London.

Brain, Lord (1962). Diseases of the Nervous System, 6th ed., p. 244. London.

Critchley, M. (1934). Practitioner, 133, 54.

Gray and Ferguson, F. R. (1933). Lancet, 1, 123

Gray, P. A., and Burtness, H. I. (1935). Endocrinology, 19, 549

Marks, V., and Rose, F. C. (1965). Hypoglycaemia, p. 75. Oxford.

Moench, L. G. (195i). Headache, 2nd ed., p. 144. Chicago.

Wilkinson, C. F., jun. (1949). Amer. Ұ. med. Sci., 218, 209. 